\title{
MODE CHOICE MODELLING OF PARATRANSIT MODES IN TRINIDAD
}

\author{
Leah Wright $^{1 *}$, Trevor Townsend ${ }^{2}$ \\ ${ }^{1,2}$ Faculty of Engineering, The University of the West Indies, Trinidad \\ ${ }^{1}$ Email: leahwright05@gmail.com*(Corresponding author) \\ ${ }^{2}$ Email: trevor.townsend@sta.uwi.edu
}

\begin{abstract}
The objective of this research was to develop a mode choice model in a small island developing states (SIDS), specifically the island of Trinidad. The public transportation system of Trinidad is dominated by paratransit modes, which have developed out of necessity due to the inadequacy of the state-owned bus service. Most modal choice models, calibrated from data in developed countries, do not consider the impacts of such para-transit modes in the choice behaviour of commuters. This research develops a discrete mode choice model based on the revealed preferences of commuters and their subjective assessment of the characteristics of the modes. The results from a nested logit model showed that invehicle travel time was a significant factor for the sample, while travel cost, was unimportant in the travellers' mode choice. Large mode-specific constants were estimated in the utility equation when compared to the other variables. This indicated a bias by individuals toward specific modes. This can be due to the current status of the public transportation system. Results highlighted that travellers, consider the illegal "PH" Taxis share more similarities to the private vehicle than to other public transportation modes. This is a significant result that can dictate the development of future policies. This research has shown the importance of incorporating paratransit modes in the mode choice models of SIDS. Future work should consider integrating latent class variables in the model analysis.
\end{abstract}

Keywords: Mode choice models, SIDS, Travel behavior.

\section{https://doi.org/10.47412/VSAZ9280}

\section{Introduction}

Small island developing states (SIDS) have unique characteristics that expose them to different social, economic and development challenges. This is mainly due to their extremely small size and population, insularity, remoteness and limited areas, and natural resources [1, 2]. These characteristics have influenced the development of the quality of life in SIDS, especially in the field of transportation. Intensely few studies have focused on a better understanding of travel behaviour in SIDS. This study develops a mode choice model in the island of Trinidad, a Caribbean SIDS utilising revealed preference data based on travellers' subjective assessment of modal characteristics.

The Republic of Trinidad \& Tobago is a twin-island state situated in the Caribbean region. The economy is with heavily based on oil \& gas, and the country has a relatively high GDP of $\$ 18,000$ USD per capita and a population of approximately 1.4 million people. Trinidad, the main island, with a total size of 5,128 square kilometres, is the most southern Caribbean island and is a few kilometres north of Venezuela. The island is classified into three main regions, North, Central 
and South Trinidad. A modern highway system connects these regions and a main road system that runs parallel to both the East-West and the North-South highways. In addition to this, there exists a Priority Bus Route (PBR) that runs along the East-West corridor in the North. The PBR is an exclusively high-occupancy vehicle route designed to provide relatively quick commutes for public transport passengers.

Due to its wealth, the country has a high per capita car ownership of over 500 vehicles per 1000 persons. This has led to significant problems of clogged roads, traffic congestion and long daily commutes. To add to the problem, there is considerable importation of used foreign cars into the island, making the availability of the private car easier to most persons [3].

The most commonly used public transportation modes in the island are the Public Transportation Service Corporation (PTSC) Bus, the maxi taxi, the route taxi and the illegally operating PH taxi. Excluding the PTSC Bus, the modes listed can be classified as paratransit modes. Paratransit modes are informal public transportation modes. They have such characteristics that they lie between the conventional public transportation and the private car and provide a service to the general public [4-6]. These type of modes have shaped the transportation system and thus, included in the analysis.

The PTSC Bus is the single government-owned mode in the land transportation system. It operates mainly full-sized units (fifty-five to sixty-five passengers), although there are some articulated units on more heavily trafficked routes as well as smaller buses for rural routes where roadway widths are more constrained. Although it has the lowest fares (it is subsidised by over three hundred million TT dollars annually), it is very unpopular, transporting less than five percent of transit users [7].

The maxi taxi service is a privately owned, paratransit service that is heavily used by travellers. Maxi taxis are mini-buses which hold between nine to twenty-five passengers. Though unregulated, fares are set by loose associations of maxi taxi owners. Each maxi taxi can only operate in one of five regions in the county. They operate like unscheduled buses from established stands and on well-known routes within their regions. There are approximately five thousand maxi taxis on the island, with an estimated annual ridership of two hundred million passenger trips [7].

The route taxi is a privately owned vehicle, usually a sedan or a minivan seating four to eight passengers and like the maxi taxi, is shared-ride and does not follow a schedule. The route taxis are registered as 'for hire' vehicles and carry a license plate with H. Like the maxi taxis; fares are set by associations. Though taxis are not limited to any route, most operators work from stands and on well-known routes based on their residential location. There are approximately twelve thousand, five hundred route taxis with an estimated ridership of one hundred and twenty-five million passengers per annum [7]. Modes similar to maxi taxis and route taxis exist in many developing countries and SIDS [8, 9].

PH taxis, known as 'pirate taxis' are not registered for hire but operate without legal sanction. Indeed, since they are the same size and carry the same registration designation of "P", $\mathrm{PH}$ taxis are physically indistinguishable from private vehicles. They formerly operated in areas not well served by legal route taxis and maxi taxis. This mode shares similar characteristics to the route taxi; however, because it operates illegally, there is no restriction on the size of vehicles used or the routes they penetrate. Additionally, while legitimate taxi drivers require a special permit and a background check for criminal activity, PH drivers operate without such a permit. 
Similarly, vehicles used as legal route taxis have to be inspected annually by the licensing authority and carry higher insurance premiums than PH cars. Consequently, since PH cars are operating illegally, their passengers are not insured against risk or injury. In recent times, these illegal taxis have competed aggressively with the route taxis and maxis and affected the livelihood of those operators.

This study examines the use of various transportation modes and models the choice behaviour of commuters in a residential community on the island of Trinidad, a Caribbean SIDS. The remainder of this paper discusses more details on the characteristics of Trinidad travellers and the results of a mode choice analysis using a multinomial logit (MNL) model and a nested logit (NL) model. Finally, a conclusion is given and future research in the direction of SIDS in the travel behaviour field.

\subsection{Transportation System Development in Caribbean SIDS}

Though developing countries and SIDS share many characteristics, SIDS have peculiar features that limit the length of the journey these modes make, the cost of a single trip, due to things such as fuel costs as well as the routes and the type of vehicles used. The geography of SIDS has a strong influence on their economy, mobility and transportations. SIDS are generally tiny, remote islands that are mountainous $[1,10,11]$. This limited area effects where individuals can live as well as the building of infrastructures. Thus, in most rural parts, many persons cannot access certain services such as public transportation, making mobility and quality of living very difficult. This also puts a restriction on the kind of public transportation modes that can be introduced into the island, making way for more unorthodox, unregulated paratransit modes. Also, the deep divide between the rich and the poor, with such notable pockets of poverty, in places with such small population [11] has influenced the type and quantity of investments into the transportation system, where more financing is given to road infrastructures, rather than improving the public transportation system.

Compared to other developing countries, SIDS are generally more economically vulnerable with unstable export earnings and high dependence on foreign and international trade [11]. This is heavily due to the remoteness and the size of the islands. The vulnerable economic behaviour of SIDS implies a strict limit on resources. Thus, projects such as the improvement of public transportation services tend to suffer. Therefore, the representation of SIDS in the travel behaviour field gives a different perspective on a common issue.

\subsection{Paratransit Modes in Developing Countries and Caribbean SIDS}

In developed countries, ridesharing has become more popular with companies such as Uber and Lyft using the programs Uberpool and Lyft line, respectively. Although not usually classified as "paratransit", they allow for multiple passengers to utilise a vehicle as it traverses a route between some O-D pair, just like a transit vehicle. Many practitioners in developed countries are incorporating rideshare modes under the umbrella Mobility as a Service (MaaS) in travel behaviour analysis [12-16]. Interestingly, this concept of ridesharing as a significant travel service option has long been applied in SIDS and developing countries due to the absence of reliable public transportation services. This notwithstanding, in Trinidad, the use of a privately owned vehicle as a "for hire" vehicle when it is not duly registered as such is illegal. 
When analysing public transportation in developing countries, paratransit modes are heavily found in the systems [17-19]. These modes generally operate in areas where there is a lack of service of the traditional, government-managed modes. In fact, in some countries, the paratransit modes dominate the public transportation system and are key modes that tackle the 'first and last mile' issue that develops in certain areas [20,21]. Although these paratransit modes cater well to those public transportation captive travellers and have the potential to improve sustainability, quality of service and accessibilities for persons, the lack of regulations and uncontrolled growth of these types of modes, causes them to add more problems to the transportation system rather than improve it $[18,20,22]$. Better analysis of these modes is needed to understand how they affect persons and the policies that should be implemented to improve the system.

There are generally two types of paratransit modes; non-motorized and motorised. In the Caribbean region, the paratransit modes are motorised. Most of the previous studies on paratransit modes in developing countries focused on physical and operational characteristics, policy, regulation and market structure, their role as feeder services, and paratransit-adaptive transportation policies for transition to sustainable systems [22, 23].

\section{Methods}

To investigate the mode choice of travellers in Trinidad, a revealed preference survey was conducted on the island in January 2018, in the North, where the capital is located. A household travel behaviour survey was administered in the Trincity area, which lies along the East-West corridor of the country. This area was selected for the study because every public transportation mode in the choice set is readily available to individuals in this community and for its diverse socio-economic and demographic community. However, this was not found to be true.

The sample size of the survey was 500 individuals. The survey was administered over eight weeks and used the techniques advised by the Central Statistical Office of Trinidad. The last birthday method was used to select who within the household should complete the questionnaire. Therefore, the adult respondent who was chosen to participate in the survey was the individual who most recently celebrated their birthday in the household. Though this is a quasi-probability method, it has been shown to give high response rates, with minimum mistakes being made by respondents when compared to other stratification methods [24].

The survey questionnaire asked respondents to indicate their mode choice for the longest trip on their work tour. In most public transportation work trips, the individual on average uses two different modes [25]. Therefore, it was necessary to determine the primary mode of transportation of the respondents. The instrument also asked respondents to state their estimated cost of travel, in-vehicle and out-of-vehicle travel times for their chosen mode as well as the modes not chosen. The survey thus relied on subjective information from respondents rather than objective data. This is in keeping with the underlying assumption of discrete choice models that consumers make decisions based on their perception of the attributes of the choices available rather than the actual attributes and that subjective data does vary from objective data [26, 27]. Furthermore, the inclusion of unscheduled paratransit modes, where there is also a high incidence of inter-modal transfers during a single tour makes objective measurement of individual waiting times impractical. 


\subsection{Discrete Choice Models}

Discrete choice models are based on utility theory, where a utility is an index of attractiveness that the individual tries to maximise [28]. The utility equation is shown in Eq (1) as;

$$
U_{i j}=V_{i j}+\varepsilon_{i j}
$$

Where:

$U_{i j}=$ the utility of individual ' $i$ ' for alternative ' $\mathrm{j}$ '.

$V_{i j}=$ the systematic component of the utility of alternative ' $\mathrm{j}$ ' for individual ' $\mathrm{i}$ '.

$\varepsilon_{i j}=$ The random portion that represents the particular taste of the individual and any measurement of observational error by the analysts.

The type of discrete model is defined by the distribution of the error term. The MNL and the NL are the most widely used discrete models for practical analysis of travel behaviour, where the latter is a generalisation of the former, that relaxes the independence of irrelevant alternative property [29]. The Nested Logit Model was used in this study.

The utility design process is a necessary part of any discrete choice model. The program BIOGEME was used for the model estimation, as this study does not focus on the estimation procedure, the emphasis is on the mode type, the parameters and the utility equation. BIOGEME is a freeware package designed for the development of research in the context of discrete choice models in general, and of Generalized Extreme Value models in particular [30]. It is designed to estimate the parameters of various discrete choice models using maximum likelihood estimation. The version used in this research was version 2.6, BisonBiogeme.

Determining the most suitable utility equation for a sample is an iterative process, and requires experience and knowledge to be executed efficiently. This process is illustrated in the flow chart in Fig 1. 
Faculty of Engineering, The UWI, St. Augustine | June $1^{\text {st }}-5^{\text {th }}, 2020$

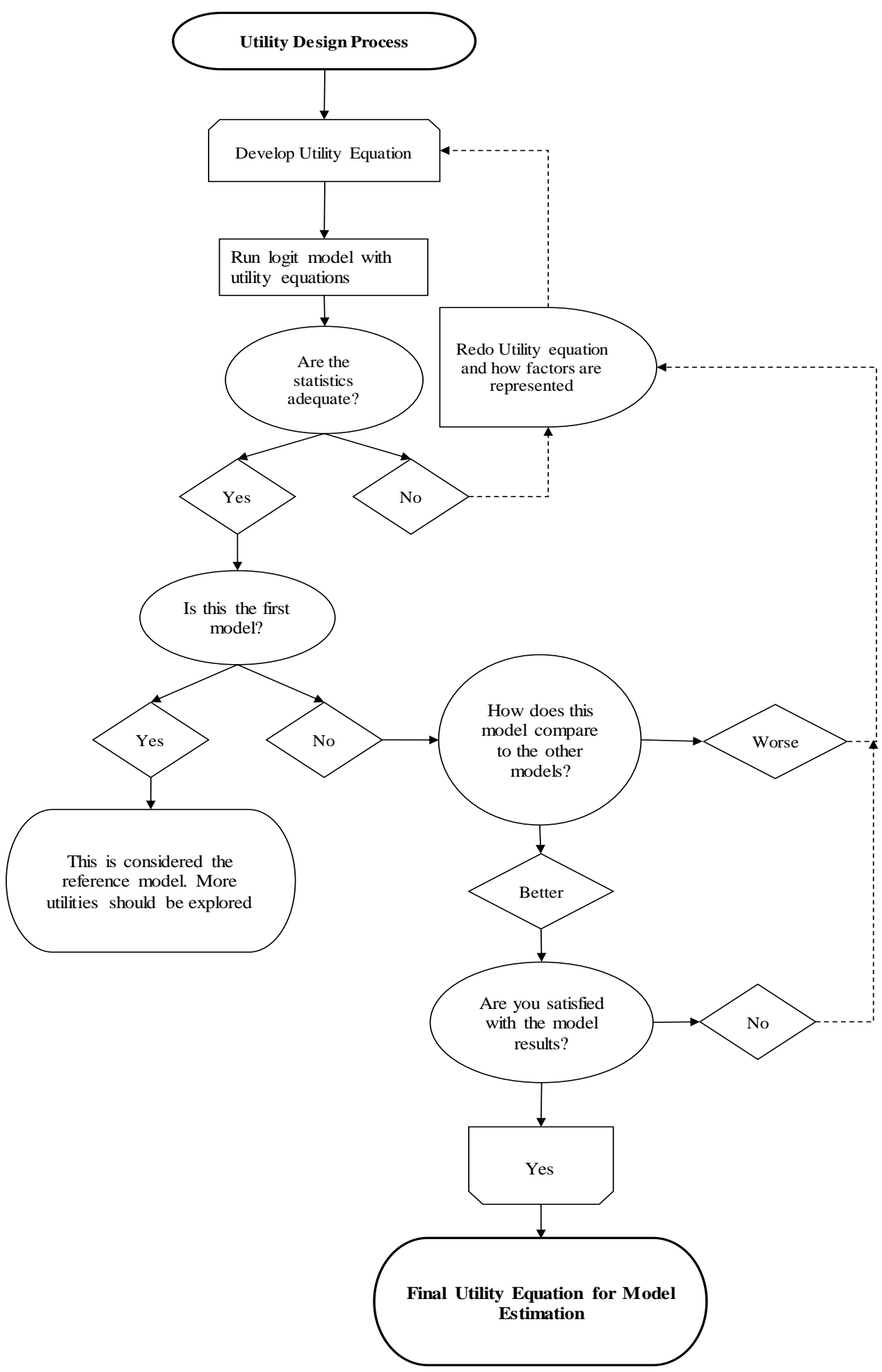

Figure 1: Utility Equation Optimisation Flowchart 


\section{Results}

The data collected indicated that approximately eighty-seven percent of the sample used the private car in their daily work tours, while twelve percent used public transportation. Additionally, of those public transportation users, thirty-eight percent used the maxi taxi as their main mode, thirteen used the route taxis, eleven percent used the PH taxi and two percent used the PTSC Bus. Thirty-one percent indicated that in one leg of their work tour, they were a passenger in a private vehicle, and used a public transportation mode (usually a maxi taxi) in the return home trip. The sample was also homogenous with income, where over sixty percent of the sample indicated a gross monthly income between ten thousand and twenty-two thousand (TT) dollars, resulting in significant representation of the middle class.

The results highlighted that most respondents worked relatively close to their homes. That is, roughly fifty-three percent of the sample lived and worked in the same regional corporation. Nonetheless, both groups of travellers had multiple trips in a tour. However, a stop for a public transportation user indicated a change in mode, while a stop for a private car user suggested a shift in purpose. Public transportation users tend to make 4-trip tours, while private car users generally made 2-trip tours.

\subsection{Nested Logit Model and Estimation}

The choice set used for the nested logit model consisted of the private car, maxi taxi, route taxi and the PH taxi. The PTSC Bus was excluded from the choice set because of the low response rate. The parameters income (Inc), in-vehicle time (IVT), out-of-vehicle time (OVT) and travel cost (TC) of the tour were used in the utility equation, shown in Eq (2).

$$
U_{j}=\gamma_{j}+\gamma_{T C} T C_{j}+\gamma_{I V T} I V T_{j}+\gamma_{O V T} O V T_{j}+\beta_{i} I n C
$$

The use of different public transportation modes in the choice set suggests that there would be similarities between the modes, and therefore warranted an analysis with an NL model. Various NL model structures were analysed. The only stable model developed consisted of two nests; a nest with the PH taxi and the private car, and the other with the maxi taxi and route taxi. (see Fig 2). It should be noted that the NL model is based on the utility equation used in the MNL model. The results showed IVT was again significant in the decision making (see Table 1 and Table 2).

The data from this sample has shown to behave non-normal, therefore, the robust t-test and p-value produced much better results than the standard t-test for the nest. In this structure the nesting parameter for nest ' $a$ ' and ' $b$ ' were 0.43 and 0.45 respectively, as shown in Table 1 and Table 2. For the BIOGEME program, the following inequalities shown in Eq 3 and Eq 4 must be satisfied in order tobtain conditions required for the nested logit theory;

$$
\begin{gathered}
\text { Nest }_{j} \geq 1 \\
0 \leq \frac{\mu}{\text { Nest }_{j}} \leq 1
\end{gathered}
$$

Where;

$\mu=1$ 
Surprisingly, there was some similarity between the private car and the $\mathrm{PH}$, which is usually considered mostly similar to the taxi. This relationship does indicate that the respondents considered the PH to have characteristics close to the private car. Though the results for nest ' $b$ ', are not ideal, the results are still favourable enough to be noteworthy, as they are significant for a $90 \%$ confidence interval.

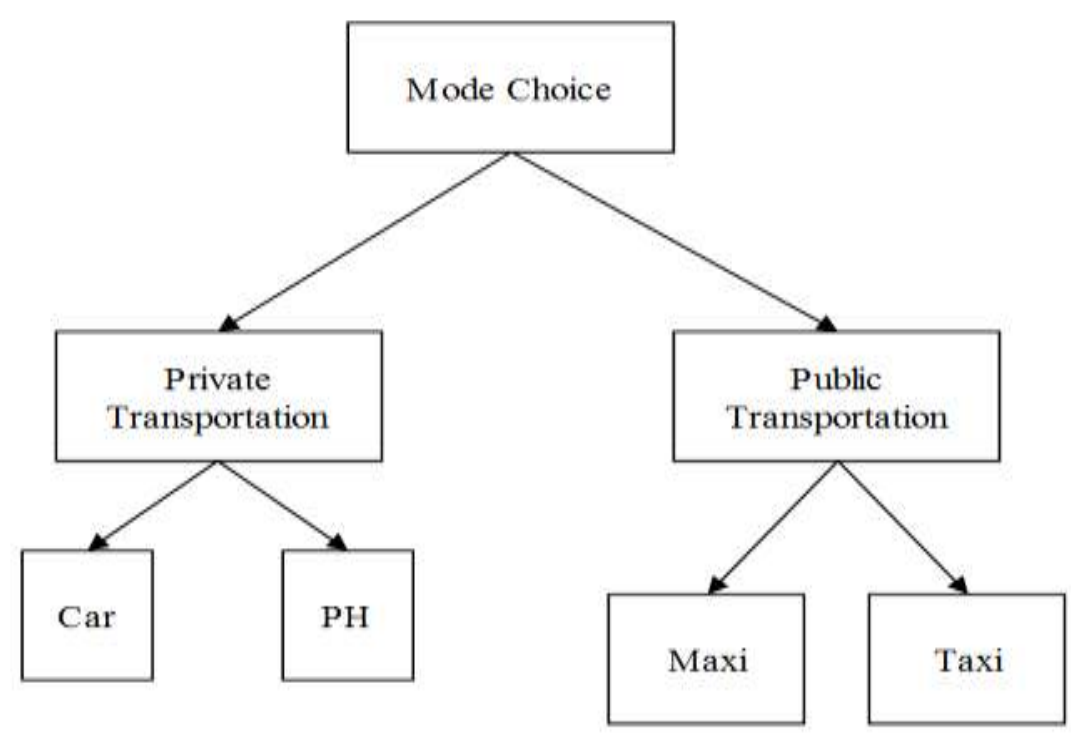

Figure 2: NL Structure

Table 1: Statistical Results for NL Model

\begin{tabular}{|c|c|c|c|c|}
\hline Parameter Name & Value & Std Error & T test & P-value \\
\hline In-Vehicle-Time & -0.0345 & 0.00900 & -3.83 & 0.00 \\
\hline \multicolumn{5}{|l|}{ Mode Constants } \\
\hline Private car & 0.00 & Fixed & & \\
\hline Maxi taxi & -4.12 & 0.509 & -8.11 & 0.00 \\
\hline PH taxi & -3.68 & 0.790 & -4.65 & 0.00 \\
\hline Route taxi & -4.66 & 0.562 & -8.30 & 0.00 \\
\hline Null log Likelihood & -378.492 & & & \\
\hline Initial log Likelihood & -378.492 & & & \\
\hline Final Log-Likelihood & -32.982 & & & \\
\hline Likelihood Ratio test & 691.012 & & & \\
\hline Rho square & 0.913 & & & \\
\hline Adjusted Rho Square & 0.897 & & & \\
\hline
\end{tabular}

TABLE 2: Statistical Results of the Nested Parameter for the NL Model 


\begin{tabular}{|l|l|l|l|l|}
\hline Parameter Name & Value & $\begin{array}{l}\text { Robust Std } \\
\text { Error }\end{array}$ & Robust T-test & P-value \\
\hline & & & & \\
\hline Nest A & 2.32 & 0.464 & 2.85 & 0.00 \\
\hline$\theta_{A}$ & 0.43 & & & \\
\hline & & & & 0.08 \\
\hline Nest B & 2.21 & & 1.73 & \\
\hline$\theta_{B}$ & 0.45 & & & \\
\hline
\end{tabular}

\section{Discussion}

As discussed previously, and shown in the results paratransit modes, whether motorised or nonmotorized, generally dominate the public transportation system is SIDS [20, 22] as compared to standard, scheduled bus or other government offered transit services. In this study, approximately $2 \%$ of the public transportation users chose PTSC bus as their mode of transportation. This is the only government-owned transit mode in the choice set. Most of the public transportation users prefer to use either maxi taxis, route taxis. This is mainly influenced by the absence of robust and well-functioning bus companies [31-34].

Furthermore, poor traffic management and a lack of enforcement have allowed paratransit modes to grow uncontrolled [32]. It should also be noted that in the subjective data set, most individuals did not give a response for the PTSC bus, indicating that the bus was not a practical option in their respective choice sets. Thus, for this reason, the PTSC bus was excluded from the analysis.

In this study, there was very high vehicle ownership, where more than $97 \%$ of the sample indicated having at least one car available in their household. Car ownership has been proved to influence travel choice $[35,36]$. With this knowledge, it can be assumed that this high car ownership has heavily influenced the behaviour of participants in this study.

The collection of travel behaviour data is not typical in Caribbean SIDS. There has been no prior study in Trinidad that collected this level of data. Furthermore, the collection of subjective data is a new concept for different agencies on the island. Due to this, there was some difficulty in the data collection, where some individuals did not give information for all modes in the data set, only the next perceivable alternative. This and the homogeneous nature of the data set could be the cause of the type of results obtained. Nonetheless, some interesting results were obtained.

The results from the MNL model, indicated that IVT was a significant parameter in the utility equation used (as shown in Table 1 and Table 2). This does follow the vast amount of literature on travel demand modelling. However, it was unexpected that the remaining parameters (TC, Inc and OVT) were not significant. This may have been primarily influenced by the homogenous nature of the sample.

The data additionally revealed large mode-specific constants, relative to the other parameters. This suggests a bias by the respondents toward the car. This finding does support the various studies on SIDS that describe a rapid increase in automobile ownership. MNL model two, without the modespecific constants, showed that IVT and Inc behaved as expected by the literature. This further 
suggests that there are variables that have not been used, that are being captured by the modespecific constants. This can be car ownership or the negative connotation with paratransit due to their unscheduled and irregular behaviour. Many car users viewed most public transportation modes as uncomfortable, inconvenient, and taking longer than the private car for the same journey. This is reinforced by MNL model 2, where the mode-specific constants were eliminated, and income was then shown to be significant in the mode choice of travellers.

\section{Conclusion}

There is limited literature on the use of mode choice models in Caribbean SIDS, especially in the island of Trinidad. Though the sample was relatively homogeneous concerning the income, mode choice and the travel cost of modes, there were some noteworthy results from the data. Models in developing countries and SIDS must include an understanding of the population's perception of the quality of the service given by the paratransit modes. This study provides a better understanding of how paratransit public transportation modes are viewed in Trinidad, where many persons' decision was governed by the in-vehicle-time of the modes. Thought the use of subjective data is not typical in the field, it has shown some interesting results in the study. Many of the respondents indicated a negative connotation with the PTSC bus system. The perceived time values of public transportation, by private car users was higher than the actual public transportation times, especially for the Bus. This suggests that only improving the travel times of the modes may not be enough. Change must be supported with information transfer to the commuters, to change their perception of the mode and therefore improve ridership of transit modes.

Furthermore, many respondents used the paratransit modes, over the government-owned PTSC Bus and the illegal PH taxi, shared similarities to the private car more than other paratransit modes in the choice set. Different variables (e.g. gender, age and comfort) were tried in many different models. However, none of them proved significant on this data set. This may be due to the quality of the data used.

Future research should include a more extensive and diverse sample, more analysis on the influence of car ownership on decisions, a cross-nested logit model and including latent choice variables in the study.

\section{References}

[1] Briguglio, L., Small island developing states and their economic vulnerabilities. World development, 1995. 23(9): p. 1615-1632.

[2] Gay, D., T. Rogers, and R. Shirley, Small island developing states and their suitability for electric vehicles and vehicle-to-grid services. Utilities Policy, 2018. 55: p. 69-78.

[3] Cervero, R., Linking urban transport and land use in developing countries. Journal of Transport and Land Use, 2013. 6(1): p. 7-24.

[4] Shimazaki, T. and M. Rahman, Physical characteristics of paratransit in developing countries of Asia. Journal of advanced transportation, 1996. 30(2): p. 5-24.

[5] Vuchic, V.R., Urban public transportation; systems and technology. 1981.

[6] Chowdhury, T.D., et al., Identifying important features of paratransit modes in Sylhet City, Bangladesh: a case study based on travelers perception. Civ Eng J, 2018. 4(4): p. 796-811. 
[7] Steer Davies Gleave, Trinidad Rapid Rail Transit System: Socio-Economic Analysis Report. 2008. p. 71.

[8] Cervero, R., Informal transport in the developing world. 2000: UN-HABITAT.

[9] Joewono, T.B. and H. Kubota, The characteristics of paratransit and non-motorized transport in Bandung, Indonesia. Journal of the Eastern Asia Society for Transportation Studies, 2005. 6: p. 262-277.

[10] Kerr, S.A., What is small island sustainable development about? Ocean \& Coastal Management, 2005. 48(7-8): p. 503-524.

[11] Everest-Phillips, M., Small, So Simple?: Complexity in Small Island Developing States. 2014: UNDP Global Centre for Public Service Excellence.

[12] Hietanen, S. Mobility as a Service: Can it be even better than owning a car. 2014 [cited 2018 12/6]; 2-4]. Available from:

https://www.itscanada.ca/files/MaaS\%20Canada\%20by\%20Sampo\%20Hietanen\%20and\%20Sa mi\%20Sahala.pdf.

[13] Holmberg, P.-E., et al., Mobility as a Service-MaaS: Describing the framework. 2016.

[14] Goodall, W., et al., The rise of mobility as a service, in Deloitte Review. 2017. p. 112-129.

[15] Jittrapirom, P., et al., Dynamic adaptive policymaking for implementing Mobility-as-a Service (MaaS). Research in Transportation Business \& Management, 2018.

[16] Jittrapirom, P., et al., Mobility as a service: A critical review of definitions, assessments of schemes, and key challenges. 2017.

[17] Dimitriou, H.T. and R. Gakenheimer, Urban transport in the developing world: A handbook of policy and practice. 2011: Edward Elgar Publishing.

[18] Pojani, D. and D. Stead, Sustainable urban transport in the developing world: beyond megacities. Sustainability, 2015. 7(6): p. 7784-7805.

[19] Wongwiriya, P., et al., User Perception of Paratransit in Thailand: Case study of Journey to School in Khon Kaen City. 土木学会論文集 D3 (土木計画学), 2016. 72(5): p. I_801-I_807.

[20] Tangphaisankun, A., F. Nakamura, and T. Okamura. Influences of paratransit as a feeder of mass transit system in developing countries based on commuter satisfaction. in Proceedings of the Eastern Asia Society for Transportation Studies Vol. 7 (The 8th International Conference of Eastern Asia Society for Transportation Studies, 2009). 2009. Eastern Asia Society for Transportation Studies.

[21] Weningtyas, W., A. Fujuwara, and J. Zhang, Does Improved level of paratransit service improve drivers' quality of life? Journal of the Eastern Asia Society for Transportation Studies, 2013. 10: p. 1367-1383.

[22] Phun, V.K. and T. Yai, State of the art of paratransit literatures in Asian developing countries. Asian Transport Studies, 2016. 4(1): p. 57-77.

[23] Basu, R., V. Varghese, and A. Jana, Comparison of traditional and emerging paratransit services in Indian metropolises with dissimilar service delivery structures. Asian Transport Studies, 2017. 4(3): p. 518-535.

[24] Lind, K. and R. Oldendick, Comparison of the accuracy of the last birthday versus the next birthday methods for random selection of household respondents. Age, 2000. 231(16): p. e7.

[25] Steer Davis Gleave, Trinidad Rapid Rail: Traffic Study Report. 2008. p. 107.

[26] Muro-Rodríguez, A.I., I.R. Perez-Jiménez, and S. Gutiérrez-Broncano, Consumer behavior in the choice of mode of transport: a case study in the Toledo-Madrid corridor. Frontiers in psychology, 2017. 8: p. 1011. 
[27] Tenenboim, E. and Y. Shiftan, Accuracy and bias of subjective travel time estimates. Transportation, 2018. 45(3): p. 945-969.

[28] Ben-Akiva, M.E. and S.R. Lerman, Discrete choice analysis: theory and application to travel demand. Vol. 9. 1985: MIT press.

[29] Koppelman, F.S. and C. Bhat, A Self Instructing Course in Mode Choice Modeling: Multinomial and Nested Logit Models. 2006, United States Department of Transportation. p. 249. [30] Bierlaire, M. BIOGEME: a free package for the estimation of discrete choice models. in Swiss Transport Research Conference. 2003.

[31] Gwilliam, K., Urban transport in developing countries. Transport Reviews, 2003. 23(2): p. 197-216.

[32] Gwilliam, K., Cities on the move-Ten years after. Research in Transportation Economics, 2013. 40(1): p. 3-18.

[33] Carruthers, R., M. Dick, and A. Saurkar, Affordability of public transport in developing countries. 2005.

[34] Domarchi, C., J.E. Coeymans, and J. de Dios Ortúzar, Shared taxis: modelling the choice of a paratransit mode in Santiago de Chile. Transportation, 2019. 46(6): p. 2243-2268.

[35] Weinberger, R. and F. Goetzke, Automobile ownership and mode choice: Learned or instrumentally rational? Travel Behaviour and Society, 2019. 16: p. 153-160.

[36] Train, K., A structured logit model of auto ownership and mode choice. The Review of Economic Studies, 1980. 47(2): p. 357-370. 